\title{
Differentiation of local tumor recurrence from radiation-induced changes after stereotactic radiosurgery for treatment of brain metastasis: case report and review of the literature
}

Philipp Kickingereder ${ }^{1 \dagger}$, Franziska Dorn ${ }^{2}$, Tobias Blau $^{3}$, Matthias Schmidt ${ }^{4}$, Martin Kocher ${ }^{5}$, Norbert Galldiks ${ }^{6,7 \dagger}$ and Maximilian I Ruge ${ }^{1^{*}+}$

\begin{abstract}
Background: Structural follow-up magnetic resonance imaging (MRI) after stereotactic radiosurgery (SRS) for brain metastases frequently displays local changes in the area of applied irradiation, which are often difficult to interpret (e.g., local tumor recurrence, radiation-induced changes). The use of stereotactic biopsy for histological assessment of these changes has a high diagnostic accuracy and can be considered as method of choice. In order to solve this relevant clinical problem non-invasively, advanced MRI techniques and amino acid positron-emission-tomography (PET) are increasingly used.

Case presentation: We report the long-term follow-up of a patient who had been treated with linear accelerator based SRS for cerebral metastases of a lung cancer. Fifty-eight months after SRS, the differentiation of local recurrent brain metastasis from radiation-induced changes using structural MRI was difficult. For further differentiation, perfusionweighted MRI (PWI), proton magnetic resonance spectroscopy (MRS), and ${ }^{11} \mathrm{C}$-methyl-L-methionine (MET) PET was performed. Due to artifacts and technical limitations, PWI MRI and MRS findings were not conclusive. In contrast, MET PET findings were suggestive for radiation-induced changes. Finally, a stereotactic biopsy for histological assessment of these changes demonstrated clearly a radiation-induced necrosis and the absence of vital tumor.

Conclusion: The use of stereotactic biopsy for histological assessment of indistinguishable lesions on structural MRI after SRS for treatment of brain metastasis represents a highly reliable method to differentiate local tumor recurrence from radiation-induced changes. In this field, results of studies with both advanced MRI techniques and amino acid PET suggest encouraging results. However, artifacts and technical limitations (e.g., lesion size) are still a problem and comparative studies are needed to investigate the relationship, diagnostic performance, and complementary character of advanced MRI techniques and amino acid PET.
\end{abstract}

Keywords: Brain metastases, Radiation-induced changes, Tumor recurrence, Stereotactic-guided biopsy, PET, Advanced MRI techniques

\footnotetext{
* Correspondence: maximilian.ruge@uk-koeln.de

${ }^{\dagger}$ Equal contributors

1 Department for Stereotaxy and Functional Neurosurgery, University of

Cologne, Kerpener Str. 62, 50937 Cologne, Germany

Full list of author information is available at the end of the article
} 


\section{Background}

Early detection of brain metastasis provided by advanced screening programs as well as improvements of treatment in general oncology is positively influencing the course of the disease and overall survival of patients with brain metastases. To date, the use of stereotactic radiosurgery (SRS) is a widely accepted treatment option for (singular) cerebral metastasis [1-3]. As a consequence, the appearance of local signal changes on follow-up MRI in the irradiated region is observed in up to $22 \%$ of cases after SRS [4]. The interpretation of findings of structural magnetic resonance imaging (MRI) at follow-up after treatment with SRS (i.e., changing patterns of contrast enhancement and alterations of T2-/FLAIR-weighted images) is difficult or even impossible in order to differentiate local tumor recurrence from radiation-induced changes [5-8]. Furthermore, little experience is reported whether and when these changes occur in patients during long-term follow-up.

We present a follow-up of more than 5 years of a patient after treatment of cerebral metastases using SRS. During follow-up, the assignment of structural MRI changes to local tumor recurrence or radiation-induced changes was difficult. Regarding this clinically relevant issue, we discuss noninvasive advanced imaging methods based on MRI (i.e., perfusion-weighted MRI (PWI), proton magnetic resonance spectroscopy (MRS), and positron-emission-tomography (PET)).

\section{Case presentation}

In November 2005, in a 58-year-old male patient an adenocarcinoma of the lung was diagnosed and he underwent multimodal treatment including resection of the upper pulmonary lobe and adjuvant chemotherapy. Nine months later (July 2006), a follow-up MRI revealed a contrast-enhancing solitary lesion in the left frontal brain, highly suggestive for a brain metastasis originating from adenocarcinoma of the lung (Figure 1). The lesion was treated by linear accelerator (LINAC) based SRS (tumor volume, $0.6 \mathrm{ml}$; surface dose, $20 \mathrm{~Gy}$; isodose level, 65\%) [9,10]. Follow-up MRI after 3 months (Figure 1) showed a decrease of contrast enhancement $>50 \%$ of the treated lesion (partial response according to the Macdonald criteria [11]) as well as a new enhancing lesion also suggestive for a metastasis in the left temporal lobe (Figure 1), which was also treated with LINAC based SRS (tumor volume, $1.2 \mathrm{ml}$; surface dose, $20 \mathrm{~Gy}$; isodose level, 65\%). The subsequent MRI performed in December 2006 showed complete remission of both metastases (images not shown).

Thirty-seven months after SRS of the left temporal metastasis, a new contrast-enhancing lesion with perifocal edema was detected in the area of applied irradiation (Figure 1). Due to further progression of size in the follow-up MRI one month later (tumor volume, $2.8 \mathrm{ml}$ ), the lesion was highly suspicious for local tumor recurrence. In order to differentiate local tumor

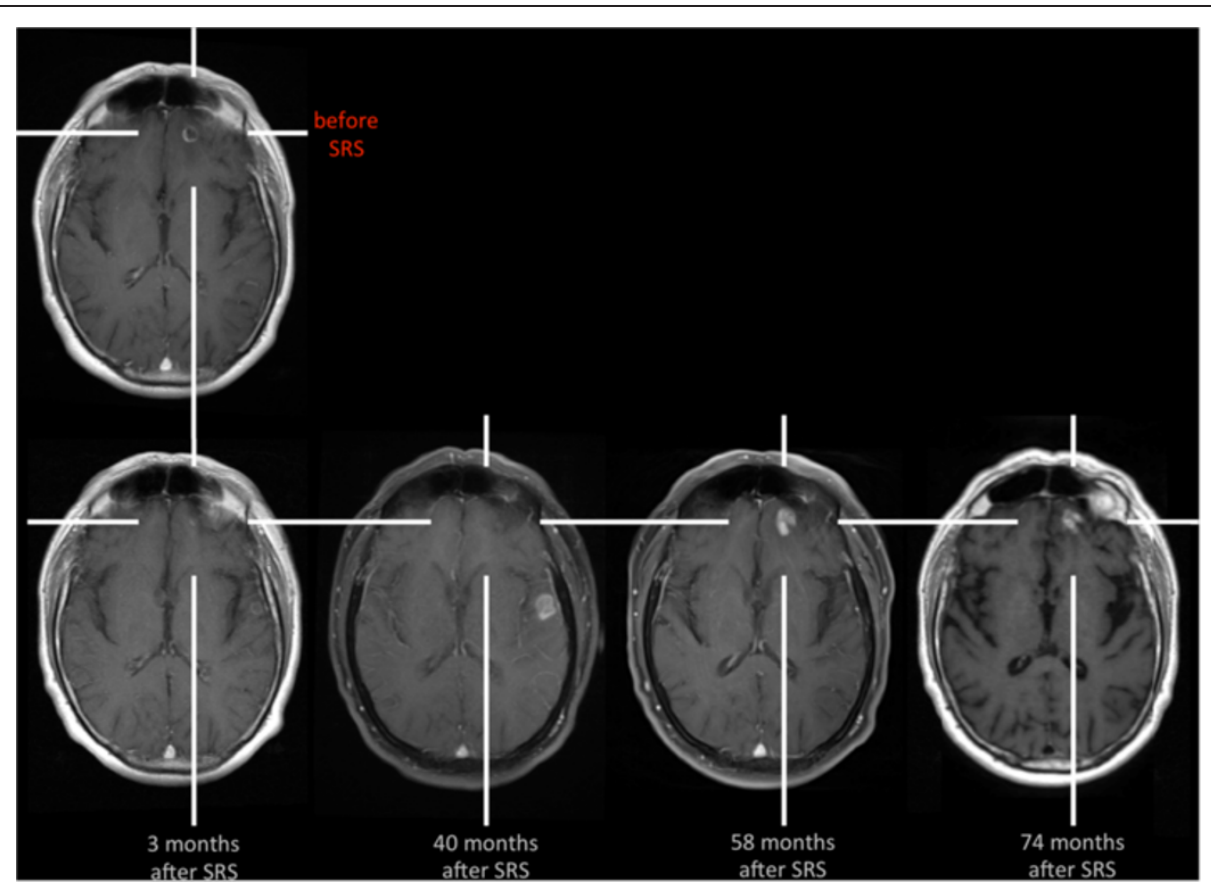

Figure 1 Contrast-enhanced MR images during the course of the disease. Fifty-eight months after LINAC SRS of the left frontal metastasis, contrast enhancement recurs within the area of applied irradiation. A differentiation of local tumor recurrence from radiation-induced changes is not possible. 


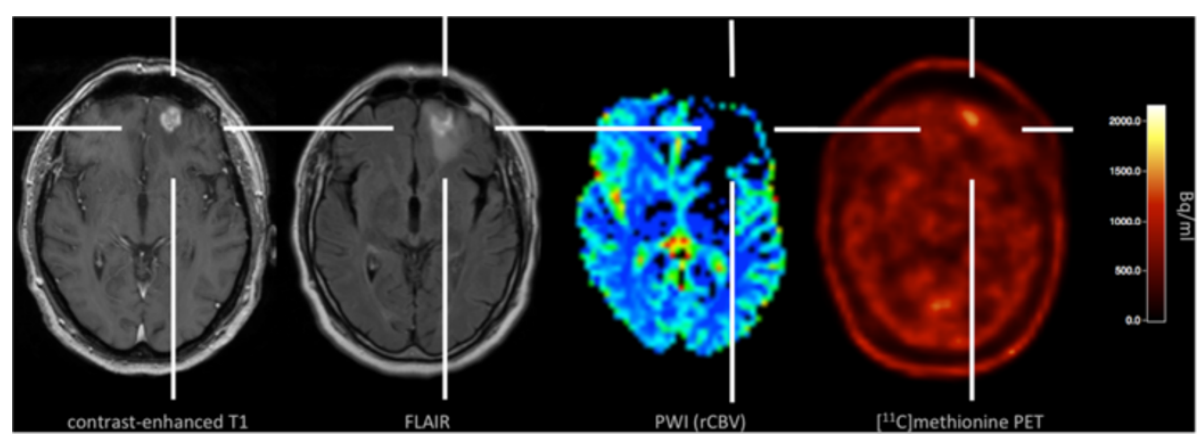

Figure 2 Multimodal imaging with structural MRI (contrast-enhanced T1- and FLAIR-weighted sequence), PWI MRI, and MET PET at the time point of suspected tumor recurrence. PWI MRI shows a perfusion deficit, areas with increased relative cerebral blood volume (rCBV) are not present. In contrast, MET PET is suggestive for radiation-induced changes (mean tumor-to-brain ratio, 1.40).

recurrence from radiation-induced changes, a stereotactic biopsy was performed. Histological assessment revealed a radiation-induced necrosis. Tumor cells were completely absent. The diagnosis of a radiation-induced necrosis was additionally confirmed by the clinical and radiological course. In follow-up MR imaging, the contrast enhancement vanished completely (Figure 1).

Fifty-eight months after SRS of the left frontal metastasis, we observed a recurrence of contrast enhancement (tumor volume, $1.8 \mathrm{ml}$ ) within the area of applied irradiation

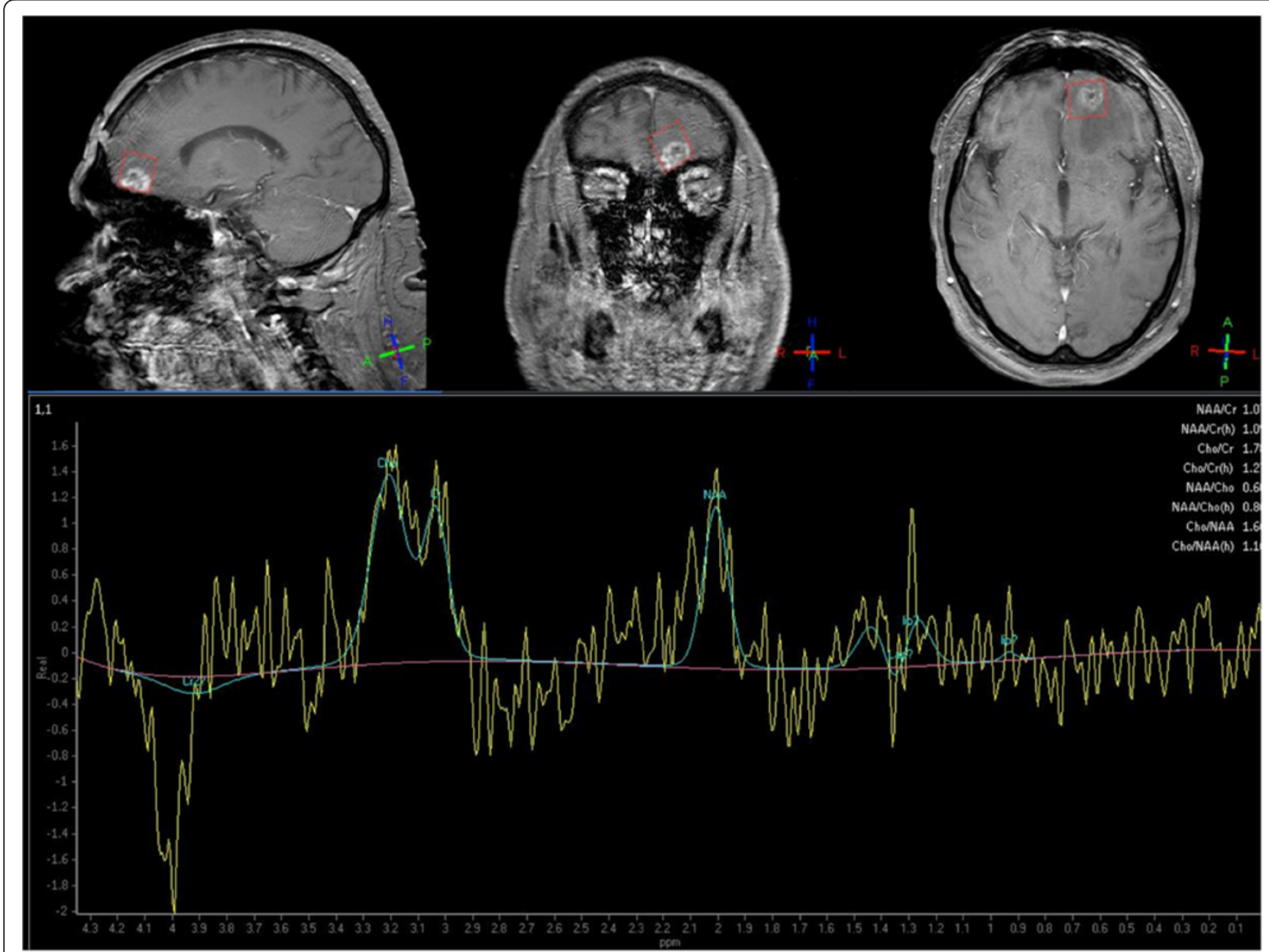

Figure 3 Spectroscopic profile of the left frontal lesion (red voxel), altered by artifacts. 
accompanied by a hyperintensity in the FLAIR-weighted MRI (Figure 1, 2). For further evaluation of this lesion, PWI MRI, MRS, and ${ }^{11} \mathrm{C}$-methyl-L-methionine (MET) PET was performed.

In detail, PWI MRI revealed a perfusion deficit with low mean transit time and low relative cerebral blood volume (rCBV), which was corresponding to the signal alterations on the FLAIR-weighted image (Figure 2). Areas with increased rCBV, however, could not be clearly identified within the perfusion deficit. Furthermore, diagnostic information of MRS was heavily influenced by artifacts and was therefore inconclusive (Figure 3). It should be noted that most probably due to the patient's unusual large frontal sinus adjacent to the left frontal lesion, the diagnostic value of PWI MRI, and MRS might have been negatively influenced. MET PET imaging of the suspicious left frontal lesion revealed a mean tumor-to-brain ratio of 1.40 (normalized against the gray matter of the unaffected right frontal cortex) (Figure 2). It has been previously demonstrated that a mean threshold of at least 1.41 or 1.42 has the best diagnostic accuracy for the identification of recurrent brain metastasis [12,13]. Accordingly, the tumor-to-brain ratio of 1.40 was suggestive for radiation-induced necrosis. Nevertheless, the ratio of 1.40 was very close to the thresholds for diagnosis of recurrent metastasis (1.41 and 1.42 , respectively) and MR imaging findings were not helpful. We therefore decided to perform a stereotactic biopsy for histological evaluation of the suspicious left frontal lesion. According to our previously reported protocol, a stereotactic ${ }^{125} \mathrm{I}$ brachytherapy (SBT) after intraoperative verification of tumor within the same surgical procedure was planned [6,14]. Intraoperatively, histological findings were consistent with radiation necrosis (Figure 4). Thus, SBT was not performed.

Follow-up MRI after 74 months showed a decrease of contrast enhancement (Figure 1). During the complete course of the disease, the patient was asymptomatic and had no neurological deficit. Furthermore, there were no clinical signs for systemic disease progression.

\section{Conclusions}

To date, contrast-enhanced structural MRI is the method of choice for follow-up of brain metastasis after treatment with SRS. However, in many patients, the differentiation of local recurrent brain metastasis from radiation-induced changes after SRS using contrastenhanced MRI is difficult [15]. This problem necessitates alternative diagnostic methods for the follow-up and management of patients with recurrent brain metastases. Various imaging techniques such as PET, single-photon emission computed tomography (SPECT), MRS, and PWI have been used for differentiation of local tumor recurrence from radiation-induced changes (Table 1).

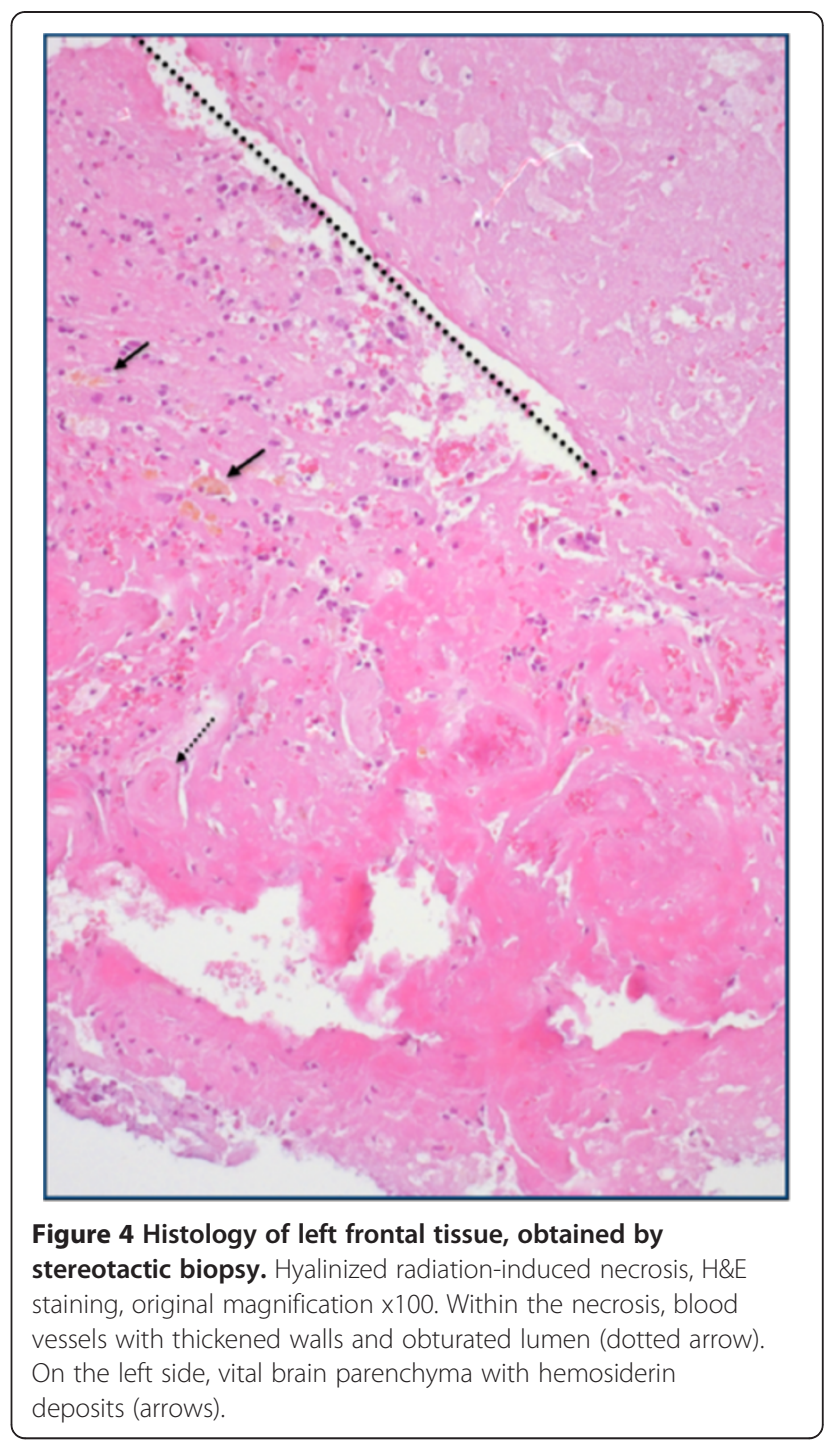

PET using 2-deoxy-[ $\left[{ }^{18}\right.$ F fluoro-D-glucose (FDG) [26] has been considered for the evaluation of brain metastasis, but the high physiologic glucose consumption of the brain and the variable glucose uptake of metastatic brain lesions limit its use. For example, in a study of 48 patients with lung cancer and brain metastasis, $33 \%$ of the brain lesions could not be clearly detected by FDG PET, although all primary lung lesions were hypermetabolic [27]. Furthermore, another limitation is a small lesion size [28]. Another study demonstrated that after SRS, FDG PET is not sensitive enough to differentiate brain metastases from radiation necrosis [20]. Additionally, the diagnostic accuracy of FDG PET may be negatively influenced since it could be observed that FDG uptake is also seen in inflammatory changes [29]. A recent study indicated that dual-phase imaging may improve the diagnostic accuracy of FDG PET for the differentiation of recurrent brain metastasis from radiation necrosis 
Table 1 Diagnostic value of several imaging techniques in differentiating tumor recurrence from radiation necrosis after SRS for brain metastases

\begin{tabular}{|c|c|c|c|c|c|c|c|c|c|}
\hline \multirow[t]{2}{*}{ Study } & \multirow[t]{2}{*}{ Imaging modality } & \multirow[t]{2}{*}{$\begin{array}{l}\text { Number of patients } \\
\text { (metastasis) }\end{array}$} & \multirow[t]{2}{*}{ Treatment (n) } & \multirow[t]{2}{*}{$\begin{array}{l}\text { Interval SRS - } \\
\text { Imaging (mo) }\end{array}$} & \multirow[t]{2}{*}{$\begin{array}{l}\text { Number of recurrent metastasis / } \\
\text { radiation-induced changes }\end{array}$} & \multicolumn{2}{|c|}{$\begin{array}{l}\text { Confirmation of } \\
\text { diagnosis }(n)\end{array}$} & \multirow[t]{2}{*}{ Sensitivity } & \multirow[t]{2}{*}{ Specificity } \\
\hline & & & & & & Histo & FU & & \\
\hline Serizawa et al., 2005 [16] & ${ }^{201}$ Thallium SPECT & $70(72)$ & SRS & 7 & $30 / 42$ & 10 & 62 & $90 \%$ & $91 \%$ \\
\hline Tsuyuguchi et al., 2003 [12] & MET PET & $21(21)$ & SRS & 12 & $9 / 12$ & 11 & 10 & $78 \%$ & $100 \%$ \\
\hline Terakawa et al., 2008 [13] & MET PET & $51(56)$ & SRS (47), EBI (4) & 17 & $24 / 32$ & 56 & 0 & $79 \%$ & $75 \%$ \\
\hline Galldiks et al., 2012 [17] & FET PET & $31(40)$ & SRS (16), SRS+WBRT (15) & 12 & $19 / 21$ & 11 & 29 & $95 \%$ & $91 \%$ \\
\hline Horky et al., 2010 [18] & Dual phase FDG PET & $25(27)$ & SRS/EBI (22), CTx (3) & 18,15 & n.r. & 16 & 11 & $95 \%$ & $100 \%$ \\
\hline \multirow[t]{2}{*}{ Chao et al., 2001 [19] } & FDG PET & $32(36)$ & SRS & 6 & 18/18 & n.r. & n.r. & $65 \%$ & $80 \%$ \\
\hline & FDG PET + MRI & $32(36)$ & SRS & 6 & $18 / 18$ & n.r. & n.r. & $86 \%$ & $80 \%$ \\
\hline Belohlavek et al., 2003 [20] & FDG PET & $25(57)$ & SRS & 8 & $8 / 49$ & 3 & 54 & $75 \%$ & $94 \%$ \\
\hline \multirow[t]{3}{*}{ Chernov et al., 2005 [21] } & FDG PET & $9(9)$ & SRS & 11 & $4 / 5$ & 5 & 4 & $50 \%$ & $80 \%$ \\
\hline & Single voxel MRS & $9(9)$ & SRS & 11 & $4 / 5$ & 5 & 4 & $50 \%$ & $100 \%$ \\
\hline & Multi voxel MRS & $9(9)$ & SRS & 11 & $4 / 5$ & 5 & 4 & $100 \%$ & $100 \%$ \\
\hline Kimura et al., 2003 [22] & Single voxel MRS & $36(43)$ & SRS & $6-12$ & $0 / 6$ & 5 & 1 & \multicolumn{2}{|c|}{$100 \% *$} \\
\hline Barajas et al., 2009 [23] & PWI & $27(30)$ & SRS & 10 & $20 / 10$ & 22 & 8 & $96 \%$ & $100 \%$ \\
\hline Hoefnagels et al., 2009 [4] & PWI & $31(34)$ & SRS & $8 / 9$ & $20 / 14$ & 11 & 23 & $70 \%$ & $100 \%$ \\
\hline Mitsuya et al., 2010 [24] & PWI & $27(28)$ & SRS & 12 & $7 / 21$ & 2 & 26 & $100 \%$ & $95 \%$ \\
\hline \multirow[t]{2}{*}{ Truong et al., 2006 [25] } & PWI & $12^{* *}$ & SRS & 9 & $10 / 2$ & 12 & 0 & \multicolumn{2}{|c|}{ PPV 80\% } \\
\hline & Multi voxel MRS & $9^{* * *}$ & SRS & 9 & $7 / 2$ & 9 & 0 & \multicolumn{2}{|c|}{ PPV 83\% } \\
\hline
\end{tabular}

*Radiation necrosis was correctly diagnosed in all cases; **3 patients were excluded due to susceptibility artifacts; ***2 patients were excluded.

$C T x=$ chemotherapy; $P W I=$ perfusion weighted imaging; $E B I=$ external beam irradiation; $F D G=2$-deoxy- $-{ }^{18} \mathrm{~F}$ Ffluoro-D-glucose; $F E T=\mathrm{O}-\left(2^{18}{ }^{18} \mathrm{~F}\right.$-Fluoroethyl)-L-tyrosine; $F L A I R=$ fluid attenuated inversion recovery;

$F U=$ confirmation of diagnosis by (serial) follow-up MRl; Histo = diagnosis proven by histological confirmation; MET $={ }^{11} \mathrm{C}$-methyl-L-methionine; $M R S=$ magnetic resonance spectroscopy; n.r. = not reported;

$P P V=$ positive predictive value for tumor recurrence; $S P E C T=$ single photon emission computed tomography; $S R S=$ stereotactic radiosurgery; $W B R T=$ whole brain radiation therapy. 
[18]. A relevant limitation of that approach is the long time interval between PET scans (range, 2-5.7 h).

Amino acid tracers are particularly useful for PET in Neurooncology because of a high amino acid uptake in tumor tissue both in metastasis and gliomas [30] together with low uptake in normal brain tissue, resulting in an enhanced tumor-to-background contrast. Previously, it has been shown that PET using MET may be effective in differentiating recurrent metastatic brain tumor from radiation-induced changes (at a threshold of 1.42 , mean tumor-to-brain ratio) with a sensitivity of $78 \%$ and a specificity of $100 \%$, respectively [12]. In a subsequent study [13], these findings could be confirmed at a similar threshold (1.41, mean tumor-to-brain ratio), at least in part, with similar sensitivity (79\%) but with lower specificity (75\%). Following these thresholds (1.41 and 1.42 , respectively), the mean tumor-to-brain ratio of 1.40 of the left frontal lesion in our patient was suggestive for radiation-induced changes. However, this ratio was very close to the reported thresholds for diagnosis of recurrent metastasis and might therefore cause several concerns regarding the correct diagnosis. For example, the calculated mean tumor-to-brain ratio may slightly vary depending on the choice of the background region-of -interest (ROI). It should be noted that the use of MET remains restricted to centers with an on-site cyclotron because of the short half-life of the ${ }^{11} \mathrm{C}$ isotope (20 min). In contrast, amino acids labeled with ${ }^{18} \mathrm{~F}$ (half-life, $110 \mathrm{~min})$ such as O-(2- ${ }^{18} \mathrm{~F}$-fluoroethyl)-L-tyrosine (FET) allow a more widespread use. In a recent study it could be demonstrated that the combination of the mean tumor-to-brain ratio and FET kinetics helps to differentiate recurrent brain metastasis tumor from radiationinduced changes with a high diagnostic accuracy [17].

A study with ${ }^{201}$ Thallium SPECT provided the correct diagnosis of recurrent brain metastasis with a sensitivity of $90 \%$ and specificity of $92 \%$, respectively [16]. However, the spatial resolution of SPECT is considerably lower than that of PET, which limits the use of this technique in clinical practice.

Beyond structural MR imaging, advanced MRI techniques such as PWI and MRS can be used successfully in order to differentiate recurrent brain metastasis from radiation-induced changes. Especially PWI can be easily incorporated into daily practice since the acquisition time is short (less than 10 minutes) [31]. In this context, the diagnostic value of PWI and MRS has been investigated by several studies [4,23-25,32]. In these studies, the sensitivity of PWI MRI ranged from of $70-100 \%$ and the specificity from $95-100 \%$, respectively. Chernov and colleagues reported a sensitivity and specificity of $100 \%$ using MRS in pilot series of 9 patients [21]. However, it should be noted that these promising results of studies with advanced MRI techniques are mostly based on a limited number of patients investigated predominantly in a retrospective setting, without histological confirmation of the diagnosis.

In addition, all of the latter mentioned MR-based techniques can be influenced negatively by technical limitations. For example, a small size or irregular shape of the lesion might affect negatively the data analysis. Inappropriate ROI placement (e.g., in heterogeneous lesions with cystic and necrotic regions) and partial volume effects may alter results. Furthermore, susceptibility artifacts due to air-containing and bony structures (e.g., sinuses, temporal bone) adjacent to the lesion may hinder data interpretation and analysis [25,33]. Additionally, for assessment of small lesions $(<2 \mathrm{ml})$ using MRS, the signal-to -noise ratio becomes a limiting factor requiring examination times inapplicable for clinical use [34]. In a previous study, the rate of unusable MRS examinations due to motion artifacts was about 7\% [35].

Regarding the reported patient, susceptibility artifacts and the small lesion size most probably caused the inconclusive findings of PWI MRI and MRS. In contrast, MET PET indicated radiation-induced changes within its limits of the previously described diagnostic accuracy. Ultimately, a stereotactic biopsy demonstrated clearly the absence of vital tumor. Stereotactic biopsy is a highly reliable diagnostic method for differentiating local tumor recurrence from radiation necrosis. Two prospective studies demonstrated the usefulness of this procedure to deliver conclusive results with a high diagnostic accuracy of more than $98 \%$ and a low risk $(<1 \%)$ of permanent complications [36,37]. Although this procedure is restricted to specialized institutions, stereotactic biopsies can be considered as method of choice, especially when diagnostic information derived from noninvasive imaging techniques are inconclusive.

In conclusion, artifacts and technical limitations of advanced MRI techniques can be a relevant problem and, furthermore, comparative studies are needed to investigate the relationship, diagnostic performance, and complementary character of advanced MRI techniques and amino acid PET. Results of multimodal imaging studies should be evaluated by stereotactic biopsy.

\section{Consent}

Written informed consent was obtained from the patient for publication of this case report and any accompanying images. A copy of the written consent is available for review by the Editor-in-Chief of this journal.

\section{Competing interests}

All authors disclose any financial and non-financial competing interests.

\section{Authors' contributions}

PK, NG, and MIR participated in the conception, organization and execution of the present work, data analysis and interpretation, and the writing and critical review of the manuscript drafts. FD participated in MRI data 
acquisition and procession, and MRI data interpretation and the critical review of manuscript drafts. TB participated in the interpretation of neuropathological findings and the critical review of manuscript drafts. MS and NG participated in PET data acquisition and procession, and PET data interpretation and the critical review of manuscript drafts. MK participated in the critical review of manuscript drafts. All authors read and approved the final manuscript.

\section{Author details}

'Department for Stereotaxy and Functional Neurosurgery, University of Cologne, Kerpener Str. 62, 50937 Cologne, Germany. ${ }^{2}$ Department of Radiology, University of Cologne, Cologne, Germany. ${ }^{3}$ Department of Neuropathology, University of Cologne, Cologne, Germany. ${ }^{4}$ Department of Nuclear Medicine, University of Cologne, Cologne, Germany. ${ }^{5}$ Department of Radiation Oncology, University of Cologne, Cologne, Germany. ${ }^{6}$ Department of Neurology, University of Cologne, Cologne, Germany. ${ }^{7}$ Institute of Neuroscience and Medicine, Research Center Jülich, Jülich, Germany.

Received: 5 November 2012 Accepted: 23 February 2013

Published: 6 March 2013

\section{References}

1. Fokas $E$, Henzel M, Engenhart-Cabillic R: A comparison of radiotherapy with radiotherapy plus surgery for brain metastases from urinary bladder cancer: analysis of 62 patients. Strahlenther Onkol 2010, 186:565-571.

2. Suh JH: Stereotactic radiosurgery for the management of brain metastases. N Engl J Med 2010, 362:1119-1127.

3. Meisner J, Meyer A, Polivka B, Karstens JH, Bremer M: Outcome of moderately dosed radiosurgery for limited brain metastases. Report of a single-center experience. Strahlenther Onkol 2010, 186:76-81.

4. Hoefnagels FW, Lagerwaard FJ, Sanchez E, Haasbeek CJ, Knol DL, Slotman BJ, Vandertop WP: Radiological progression of cerebral metastases after radiosurgery: assessment of perfusion MRI for differentiating between necrosis and recurrence. J Neurol 2009, 256:878-887.

5. Plowman PN: Stereotactic radiosurgery. VIII. The classification of postradiation reactions. Br J Neurosurg 1999, 13:256-264.

6. Ruge MI, Kickingereder P, Grau S, Hoevels M, Treuer H, Sturm V: Stereotactic biopsy combined with stereotactic (125)iodine brachytherapy for diagnosis and treatment of locally recurrent single brain metastases. J Neurooncol 2011 Oct, 105(1):109-18. Epub 2011 Apr 11.

7. Peterson AM, Meltzer CC, Evanson EJ, Flickinger JC, Kondziolka D: MR imaging response of brain metastases after gamma knife stereotactic radiosurgery. Radiology 1999, 211:807-814.

8. Huber PE, Hawighorst H, Fuss M, van Kaick G, Wannenmacher MF, Debus J. Transient enlargement of contrast uptake on MRI after linear accelerator (linac) stereotactic radiosurgery for brain metastases. Int I Radiat Oncol Biol Phys 2001, 49:1339-1349.

9. Kocher M, Maarouf M, Bendel M, Voges J, Muller RP, Sturm V: Linac radiosurgery versus whole brain radiotherapy for brain metastases. A survival comparison based on the RTOG recursive partitioning analysis. Strahlenther Onkol 2004, 180:263-267.

10. Ruge MI, Kocher M, Maarouf M, Hamisch C, Treuer H, Voges J, Sturm V: Comparison of stereotactic brachytherapy (125 iodine seeds) with stereotactic radiosurgery (LINAC) for the treatment of singular cerebral metastases. Strahlenther Onkol 2011, 187:7-14.

11. Macdonald DR, Cascino TL, Schold SC Jr, Cairncross JG: Response criteria for phase II studies of supratentorial malignant glioma. J Clin Oncol 1990, 8:1277-1280.

12. Tsuyuguchi N, Sunada I, Iwai $Y$, Yamanaka K, Tanaka K, Takami T, Otsuka $Y$, Sakamoto S, Ohata K, Goto T, Hara M: Methionine positron emission tomography of recurrent metastatic brain tumor and radiation necrosis after stereotactic radiosurgery: is a differential diagnosis possible? J Neurosurg 2003, 98:1056-1064

13. Terakawa Y, Tsuyuguchi N, Iwai Y, Yamanaka K, Higashiyama S, Takami T, Ohata K: Diagnostic accuracy of 11C-methionine PET for differentiation of recurrent brain tumors from radiation necrosis after radiotherapy. J Nucl Med 2008, 49:694-699.

14. Ruge MI, Suchorska B, Maarouf M, Runge M, Treuer H, Voges J, Sturm V: Stereotactic 125iodine brachytherapy for the treatment of singular brain metastases: closing a gap? Neurosurgeny 2011, 68:1209-1218. discussion 1218-1209.
15. Dooms GC, Hecht S, Brant-Zawadzki M, Berthiaume Y, Norman D, Newton TH: Brain radiation lesions: MR imaging. Radiology 1986, 158:149-155.

16. Serizawa T, Saeki N, Higuchi Y, Ono J, Matsuda S, Sato M, Yanagisawa M, luchi T, Nagano O, Yamaura A: Diagnostic value of thallium-201 chloride single-photon emission computerized tomography in differentiating tumor recurrence from radiation injury after gamma knife surgery for metastatic brain tumors. J Neurosurg 2005, 102(Suppl):266-271.

17. Galldiks N, Stoffels G, Filss CP, Piroth MD, Sabel M, Ruge Ml, Herzog H, Shah NJ, Fink GR, Coenen HH, Langen KJ: Role of O-(2-18F-Fluoroethyl)-LTyrosine PET for Differentiation of Local Recurrent Brain Metastasis from Radiation Necrosis. J Nucl Med 2012, 53:1367-1374.

18. Horky LL, Hsiao EM, Weiss SE, Drappatz J, Gerbaudo VH: Dual phase FDGPET imaging of brain metastases provides superior assessment of recurrence versus post-treatment necrosis. J Neurooncol 2011, 103:137-146.

19. Chao ST, Suh JH, Raja S, Lee SY, Barnett G: The sensitivity and specificity of FDG PET in distinguishing recurrent brain tumor from radionecrosis in patients treated with stereotactic radiosurgery. Int J Cancer 2001, 96:191-197.

20. Belohlavek O, Simonova G, Kantorova I, Novotny J Jr, Liscak R: Brain metastases after stereotactic radiosurgery using the Leksell gamma knife: can FDG PET help to differentiate radionecrosis from tumour progression? Eur J Nucl Med Mol Imag 2003, 30:96-100.

21. Chernov M, Hayashi M, Izawa M, Ochiai T, Usukura M, Abe K, Ono Y, Muragaki Y, Kubo O, Hori T, Takakura K: Differentiation of the radiationinduced necrosis and tumor recurrence after gamma knife radiosurgery for brain metastases: importance of multi-voxel proton MRS. Minim Invasive Neurosurg 2005, 48:228-234.

22. Kimura T, Sako K, Tanaka K, Gotoh T, Yoshida H, Aburano T, Tanaka T, Arai H, Nakada T: Evaluation of the response of metastatic brain tumors to stereotactic radiosurgery by proton magnetic resonance spectroscopy, $201 \mathrm{TICl}$ single-photon emission computerized tomography, and gadolinium-enhanced magnetic resonance imaging. J Neurosurg 2004, 100:835-841.

23. Barajas RF, Chang JS, Sneed PK, Segal MR, McDermott MW, Cha S: Distinguishing recurrent intra-axial metastatic tumor from radiation necrosis following gamma knife radiosurgery using dynamic susceptibility-weighted contrast-enhanced perfusion MR imaging. AJNR Am J Neuroradiol 2009, 30:367-372.

24. Mitsuya $K$, , Nakasu Y, Horiguchi S, Harada H, Nishimura T, Bando E, Okawa H, Furukawa Y, Hirai T, Endo M: Perfusion weighted magnetic resonance imaging to distinguish the recurrence of metastatic brain tumors from radiation necrosis after stereotactic radiosurgery. J Neurooncol 2010, 99:81-88.

25. Truong MT, St Clair EG, Donahue BR, Rush SC, Miller DC, Formenti SC, Knopp EA, Han K, Golfinos JG: Results of surgical resection for progression of brain metastases previously treated by gamma knife radiosurgery. Neurosurgeny 2006, 59:86-97. discussion 86-97.

26. Di Chiro G, DeLaPaz RL, Brooks RA, Sokoloff L, Kornblith PL, Smith BH, Patronas NJ, Kufta CV, Kessler RM, Johnston GS, et al: Glucose utilization of cerebral gliomas measured by [18F]fluorodeoxyglucose and positron emission tomography. Neurology 1982, 32:1323-1329.

27. Lee HY, Chung JK, Jeong JM, Lee DS, Kim DG, Jung HW, Lee MC: Comparison of FDG-PET findings of brain metastasis from non-small-cell lung cancer and small-cell lung cancer. Ann Nucl Med 2008, 22:281-286.

28. Thompson TP, Lunsford LD, Kondziolka D: Distinguishing recurrent tumor and radiation necrosis with positron emission tomography versus stereotactic biopsy. Stereotact Funct Neurosurg 1999, 73:9-14.

29. Chen W: Clinical applications of PET in brain tumors. J Nucl Med 2007, 48:1468-1481

30. Grosu AL, Astner ST, Riedel E, Nieder C, Wiedenmann N, Heinemann F Schwaiger M, Molls M, Wester HJ, Weber WA: An interindividual comparison of O-(2- [(18)F]Fluoroethyl)-L-Tyrosine (FET)- and L-[Methyl(11)C]Methionine (MET)-PET in patients with brain gliomas and metastases. Int J Radiat Oncol Biol Phys 2011, 81:1049-1058.

31. Dhermain $\mathrm{FG}$, Hau P, Lanfermann $\mathrm{H}$, Jacobs $\mathrm{AH}$, van den Bent $\mathrm{MJ}$ : Advanced MRI and PET imaging for assessment of treatment response in patients with gliomas. Lancet Neurol 2010, 9:906-920.

32. Kimura T, Sako K, Tohyama Y, Aizawa S, Yoshida H, Aburano T, Tanaka K, Tanaka T: Diagnosis and treatment of progressive space-occupying radiation necrosis following stereotactic radiosurgery for brain metastasis: value of proton magnetic resonance spectroscopy. Acto Neurochir (Wien) 2003, 145:557-564. discussion 564. 
33. Haroon HA, Patankar TF, Zhu XP, Li KL, Thacker NA, Scott MJ, Jackson A: Comparison of cerebral blood volume maps generated from $\mathrm{T}^{*}$ and $\mathrm{T} 1$ weighted MRI data in intra-axial cerebral tumours. Br J Radiol 2007, 80:161-168.

34. Lanfermann $\mathrm{H}$, Herminghaus $\mathrm{S}$, Pilatus $\mathrm{U}$, Hattingen $\mathrm{E}$, Zanella F: Value of $1 \mathrm{H}-\mathrm{MR}$-spectroscopy in differential diagnosis and grading of intracranial tumours. Dtsch Arztebl 2004, 101:A649-A655.

35. Moller-Hartmann W, Herminghaus S, Krings T, Marquardt G, Lanfermann H, Pilatus $U$, Zanella FE: Clinical application of proton magnetic resonance spectroscopy in the diagnosis of intracranial mass lesions. Neuroradiology 2002, 44:371-381.

36. Heper AO, Erden E, Savas A, Ceyhan K, Erden I, Akyar S, Kanpolat Y: An analysis of stereotactic biopsy of brain tumors and nonneoplastic lesions: a prospective clinicopathologic study. Surg Neurol 2005, 64(Suppl 2):S82-S88.

37. Kreth FW, Muacevic A, Medele R, Bise K, Meyer T, Reulen HJ: The risk of haemorrhage after image guided stereotactic biopsy of intra-axial brain tumours-a prospective study. Acta Neurochir (Wien) 2001, 143:539-545. discussion 545-536.

doi:10.1186/1748-717X-8-52

Cite this article as: Kickingereder et al:: Differentiation of local tumor recurrence from radiation-induced changes after stereotactic radiosurgery for treatment of brain metastasis: case report and review of the literature. Radiation Oncology 2013 8:52.

\section{Submit your next manuscript to BioMed Central and take full advantage of:}

- Convenient online submission

- Thorough peer review

- No space constraints or color figure charges

- Immediate publication on acceptance

- Inclusion in PubMed, CAS, Scopus and Google Scholar

- Research which is freely available for redistribution 